\title{
ELITES, PARTIDOS E COMPETIÇÃO POLÍTICA: Brasil e Argentina
}

\section{INTRODUÇÃO}

\author{
Gabriela Tarouco \\ Paulo Fábio Dantas Neto**
}

Competição política é um elemento fundamental da democracia. No processo de construção da democracia nos países da América Latina, a competição tem sido objeto de análises da Ciência Política e foi também a motivação deste dossiê.

Brasil e Argentina têm abrigado, desde sua redemocratização, eleições disputadas por competidores numerosos e legislaturas multipartidárias. Esse quadro pode resultar em dificuldades para o Poder Executivo e em complexidade para os eleitores, mas, sem dúvida, aponta para a construção de sistemas políticos altamente competitivos. A competição perpassa todos os artigos aqui reunidos, seja entre partidos, dentro dos partidos, entre elites, dentro das instituições. Especialmente no que diz respeito às elites e às instituições políticas, os autores pretendem oferecer sua principal contribuição.

\footnotetext{
* Universidade Federal de Pernambuco.

Rua Acadêmico Hélio Ramos, s/n - $14^{\circ}$ andar, Cidade Universitária. Cep: 50.670-901. Recife - Pernambuco - Brasil. gabrielat@uol.com.br

${ }^{* *}$ Universidade Federal da Bahia. Faculdade de Filosofia e Ciências Humanas. Centro de Estudos e Pesquisas em Humanidades.

Estrada de São Lázaro, 197. Cep: 40210-730. Federação Salvador - Bahia Brasil.pfabio@ufba.br
}

A ênfase institucionalista da ciência política contemporânea tem nos levado, às vezes, a negligenciar a importância de estudar - e mobilizar como variáveis explicativas - aspectos relativos às elites, suas preferências e seus comportamentos. Os artigos deste dossiê enfrentam o desafio de buscar a compreensão da competição política em variáveis não institucionais, porque se debruçam sobre unidades de análise em que as macroinstituições são basicamente as mesmas, ainda que apresentem, como óbvio, diferenças de formato ou de intensidade na incidência de cada um dos elementos básicos que as constituem. $\mathrm{O}$ federalismo, o sistema eleitoral proporcional e o sistema de governo presidencialista estão presentes nas unidades de espaço e de tempo comparadas ou detalhadas em estudos de caso. Tais instituições, constantes, não podem, portanto, explicar a rica variedade nos formatos e nos conteúdos de competição política dos objetos estudados nos artigos.

Os autores aqui reunidos buscam, então, suas respostas não só nas instituições, mas também nas preferências de elites e seus discursos, preferências de políticos e partidos 
e suas estratégias e na estrutura econômica das circunscrições em que se dá a competição.

Competição política, por outro lado, é algo que pode se apresentar - em diferentes países, ou diferentes momentos da história política de um país - com variados graus de institucionalização. Pode ser centralmente um fenômeno de politics, mas varia o grau em que incorpora, também, traços de polity. Formatos e padrões de competição política, na medida em que se estabilizem, podem ter papéis estruturantes da política e condicionantes das estratégias dos atores políticos, ao tempo em que também constituem resultado institucional da interação das estratégias.

Os artigos deste dossiê, para além de suas contribuições específicas e substantivas sobre a competição política nos contextos federativos sobre os quais se debruçam, terminam também sinalizando possibilidades de uma reflexão sobre o trato metodológico da competição política como variável dependente e (ou) independente, em conexões causais que se possam entabular para melhor conhecimento sobre instituições e atores políticos.

Um trabalho de André Marenco, de 2008, ${ }_{1}$ aborda um problema de caráter mais geral, do qual a consideração acima sobre a plasticidade do status metodológico da compeA tição política pode ser um recorte. Trata-se do N problema - já bem visitado pela literatura es$\underset{\dot{8}}{\dot{8} \mathrm{p} p}$ pecializada - da "institucionalização das instituições", o qual, no trabalho citado, é apontado como espécie de calcanhar de Aquiles do então chamado neoinstitucionalismo. Conforme seu argumento, estudos sobre elites políticas $\therefore$ (na medida em que resgatem o que o autor ¿ chama de viés analítico da teoria das elites e §ं não o seu mais conspícuo viés normativo) po-

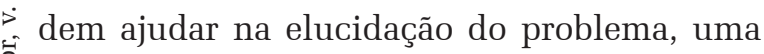
vez que tais elites não desvaneceram como objeto empírico e também porque, ao se tratar de sua "produção" e reprodução em contextos

${ }^{1}$ MARENCO, André. "Estudos de elites políticas explicam como instituições tornam-se instituições?” BIB, São Paulo, n. $65, \mathrm{I}^{\mathrm{O}}$ semestre de 2008 , p. 5-26. contemporâneos, trata-se “... de oportunidades e obstáculos oferecidos pela competição política aos indivíduos originalmente portadores de diferentes recursos sociais". A esse argumento é possível aduzir (ou, a partir dele, inferir) que a competição política oferecerá tais obstáculos e oportunidades desde que seja um processo “institucionalizável”, isto é, capaz de, pela interação de regras e estratégias, adquirir, nos termos do mesmo autor, "...estabilidade e rotina, convertendo suas regras em padrões de conduta capazes de enquadrar a ação de seus membros". A materialização dessa possibilidade é a constituição de variados formatos e diferentes padrões de competição.

Apresenta-se, desse modo, no mínimo, uma afinidade entre o argumento de Marenco e as variadas entradas que os autores reunidos neste dossiê usaram para aproximar seus artigos de territórios de intersecção entre elites e instituições. Por outro lado, se, do conjunto do dossiê, não se extraem comparações entre Brasil e Argentina (só um dos artigos a isso se propõe), em cada um surge alguma pista estimulante de uma possível agenda de pesquisa que venha a operar tais comparações nesses territórios de intersecção.

De fato, é mais razoável esperar que distintos tipos de elites, com diferentes estratégias de relação com o Estado, respondam mais a diferentes conformações da estrutura econômica - como argumentam Behrend \& Bianchi no seu artigo sobre províncias argentinas - do que a incentivos institucionais. A razoabilidade e abrangência dessa proposição empresta ao trabalho desses autores a possibilidade de oferecer uma matriz conceitual operativa para análise do mesmo tema em outros universos empíricos, aí residindo, em consequência, também uma indicação de rota para estudos comparativos entre diferentes países, inclusive entre os dois enfocados neste dossiê.

Também não é nas instituições que encontraremos explicações para as estratégias competitivas adotadas pelas elites. Nos artigos de Pereira e de Madeira et al., é o contexto, 
combinado a preferências políticas flexíveis, que informa o conteúdo dos discursos. A adaptação é uma estratégia que permite a consolidação dos atores estudados nos seus respectivos ambientes.

No caso minuciosamente esquadrinhado por Pereira, mostra-se como políticos podem adaptar-se a regras e contextos institucionais, ainda que possam conservar e utilizar, parcialmente, referências ideológicas, simbólicas e procedimentais pertinentes ao tipo de elite política a partir da qual iniciam a sua trajetória. E, como mostram Madeira et al., também partidos, espaços organizados e institucionalmente ancorados de ação coletiva, tornam-se elites e agem explicitamente como tal, sob o influxo de uma trajetória, ao longo do tempo e diante de desafios postos pela competição.

A adaptação, portanto, é estratégia praticável por atores individuais, facções de elites políticas e por grupos políticos institucionalizados, que não podem viver e realizar seu mister se não se comportarem também como atores. Assim, partidos políticos são, eles mesmos, instituições, além de atores coletivos, minorias ativas (elites, pois) que também são autoras de regras do jogo (renováveis).

A configuração do sistema partidário (sua nacionalização, fragmentação, polarização, etc.) é uma instituição que varia nos casos estudados neste dossiê. Entre Brasil e Argentina e entres as unidades subnacionais nos dois países há grandes diferenças que afetam, por sua vez, de formas diversas, os governos e as políticas públicas. É isso que nos mostram os artigos de Simpson e de Gonzalez \& Cáceres.

A fragmentação dificulta a gestão da coalizão, aumentando a necessidade de os governantes alocarem recursos para preservar a base aliada e a sua dificuldade de manter gabinetes estáveis, o que restringe sua discricionariedade para alocar recursos em gastos sociais, que é onde eles rendem mais votos. É para isso que aponta a comparação que Gonzalez \& Cáceres fazem entre províncias argentinas: resultados eleitorais que reduzam a competitividade elei- toral na província e diminuam a fragmentação partidária no Legislativo permitem maior controle do governador sobre sua coalizão e, com isso, na sequência, maior gasto social, pois se reduzem os custos de transação política. Na coordenação de políticas públicas entre os níveis federal e local, o sistema partidário também faz diferença. Como argumenta Simpson em seu artigo, a nacionalização e a dinâmica dos sistemas partidários do Brasil e da Argentina são muito distintas e centrais para o sucesso de políticas públicas universais e duradouras, que demandem relações intergovernamentais cooperativas.

De fato, esperar que instituições expliquem tudo seria dogmático. Neoinstitucionalismo não é religião, é uma teoria, e teorias devem ser alvos de reiterados testes empíricos. Assim caminha o conhecimento científico. Lacunas empíricas da teoria institucionalista devem nos devolver à reflexão teórica e à busca de explicações alternativas. É o que fazem os artigos do dossiê, combinando análises de restrições e incentivos institucionais à de fatores contextuais, econômicos, e à da dinâmica da competição política.

O desenho institucional do federalismo gera incentivos à diferenciação dos processos decisórios e das relações intergovernamentais, mas o grau dessa diferenciação depende de variáveis econômicas (Beherend \& Bianchi) e de estratégias territoriais dos partidos (Simpson). O presidencialismo de coalizão gera incentivos à formação de alianças, mas a dinâmica da competição faz variarem as estratégias e agendas e até identidades políticas (Madeira et al.). As regras da competição majoritária local induzem a estratégias distintas daquelas resultantes da competição proporcional, mas as escolhas dos atores respondem também a imperativos de seus compromissos como elites locais (Pereira). A autonomia orçamentária é comum a todas as províncias argentinas, mas a discricionariedade dos governos varia de acordo com o seu sucesso nas eleições legislativas (Gonzalez \& Cáceres). 
Neste dossiê, nenhum artigo se ocupa de explicar as instituições, nem sua criação, nem as mudanças ou sua decadência. Aqui o desenho institucional é tomado como dado, como o ambiente em que as elites escolhem suas estratégias competitivas. Todos os artigos chamam a atenção para o espaço de discricionariedade que as instituições deixam às escolhas das elites. Ao mesmo tempo, a leitura do conjunto dos artigos permite divisar portas entreabertas através das quais pedem passagem futuras análises sobre o trajeto inverso, possível nessa via de dupla mão entre elites e instituições.

Entendemos que aí está um desafio teórico importante e uma agenda de pesquisa promissora, para a qual esperamos ter despertado o interesse dos leitores deste dossiê.

Recebido para publicação em 03 de agosto de 2017 Aceito em 07 de agosto de 2017

Gabriela Tarouco - Doutora em Ciência Política pelo IUPERJ. Professora adjunta na Universidade Federal de Pernambuco. Publicação recente: The role of political parties in electoral governance: delegation and the quality of elections in Latin America. Election Law Journal, v. 15, p. 83-95, 2016.

Paulo Fábio Dantas Neto - Doutor em Ciências Humanas/Ciência Política pelo Iuperj. Professor da Universidade Federal da Bahia. Faculdade de Filosofia e Ciências Humanas. Departamento de Política. Trabalha com temas relacionados a Elites Políticas e a Pensamento Político Brasileiro. Publicou, entre outros textos, o livro "Tradição, autocracia e carisma: a política de Antônio Carlos Magalhães na modernização da Bahia (1954-1974)”, pela editora da UFMG (Belo Horizonte), em 2006. 